together in a coordinated way to achieve the green paper's objectives then occupational health has an important role. European legislation is likely to press for increased emphasis on occupational health. Active government support of occupational health services in Britain (as proposed by the House of Lords Select Committee on Science and Technology 1983) could ensure these services are developed so that they can make a significant contribution to health promotion. Such action could also influence the European approach to occupational health screening services, which may otherwise focus on procedures of doubtful benefit. It is therefore timely (if somewhat belated) to introduce into the government's strategy on health a scheme for improving occupational health services for all employees. This need not be expensive as the costs are borne by employers. Government initiatives on occupational health are long overdue and this is its opportunity to act.

\section{Problems in achieving targets}

The consultative document has been criticised for identifying key areas and setting targets only where data exist on the size of the problem. For occupational health a major difficulty is the paucity of good quality databases on the size of the work related health problem. The Health and Safety Executive has started to tackle the issue but the Reporting of Injuries, Diseases, and Dangerous Occurrence Regulations has been unevenly successful. ${ }^{14}$ For diseases the regulations are a failure. The specific new initiatives for respiratory disease surveillance ${ }^{13}$ and now others for urothelial tumours and haematological disorders should gather more accurate information, but as yet we have not shown the same enthusiasm or initiative as the United States Public Health Service in attempting to tackle the serious deficiencies in occupational health and safety surveillance, ${ }^{15}$ and in identifying occupational "sentinel health" events. ${ }^{16}$ Without this information we do not know the size of the problem, but it seems largely based on known underestimates. Its contribution to the ill health of the nation is considerable on present statistics. Perhaps if and when we have a better estimate, the resources might be made available to tackle a sizable portion of the problem at the heart of the consultative document: the need to improve the health of the nation.

\section{Conclusions}

Improving the health of the nation includes the health of employed people-indeed it could be argued that as they are the money earners, their health has particular importance. The consultative document pays little attention to occupational health practice. Yet it is at the workplace, with thousands of qualified professionals serving millions of employees, that special attention could be paid to health promotion in general as well as attacking the unacceptable level of work related disease and injury which weakens the economic and physical health of the country. The overall goals in the Department of Health's proposals are ideally suited to action from these occupational health practitioners. Their skills and their opportunity for intervention makes them essential, perhaps unique, players in the game plan. The fact that the document largely ignores them and the opportunity they provide to influence the nation's health is a serious omission requiring rectification. (Cm 1523.)

2 Health and Safety Executive. Health and Safery statistics 1988/89. London: HMSO, 1990. (Employment gazette 98: occasional supplement No 1.)

3 Schilling. RSF. Health protection and prevention at work. $\mathrm{Br} \mathcal{O}$ Ind Med 1989;46:683-8

4 Fox AJ, Adelstein AM. Occupational mortality: work or way of life? 7 Epidemiol Community Health 1978;32:73-8.

5 Legge TM. In: Henry SA, ed. Industrial maladies. London: Oxford University Press, 1934.

6 Harrington JM. The health of the health care workers. The Ernestine Henry Lecture 1990. I R Coll Physicians Lond 1990;24:189-95.

7 Pless IB. Accident prevention. BMF 1991;303:462-4.

8 Olsen $O$, Kristensen TS. Impact of work environment on cardiovascular diseases in Denmark. I Epidemiol Community Health 1991;45:4-10.

9 Doll R, Peto R. The causes of cancer. Oxford: Oxford University Press, 1981.

10 Harrington JM, Saracci R. Occupational cancer. Raffle PAB, Adams P, Baxter P, Lee WR, eds. Hunter's diseases of occupation. 8th ed. Sevenoaks: Hodder and Stoughton (in press).

11 Williams CJ. Cancer. BMF 1991;303:576-7.

12 Aw T-C, Harrington JM. Industrial accidents. BMY 1989;303:68-9.

13 Meridith SK, Taylor VM, McDonald JC. Occupational respiratory disease in the United Kingdom, 1989: a report to the British Thoracic Society and the United Kingdom, 1989: a report to the British Thoracic Society and
the Society of Occupational Medicine by the SWORD project group. the Society of Occupational
$B r f$ Ind Med 1991;48:292-8.

14 Carter JT. There's a lot of it about. Br F Ind Med 1991;48:289-91.

15 Baker EL, ed. Surveillance in occupational health and safety. Am $\mathcal{f}$ Public Health 1989;79(Suppl 1):64.

16 Mullan RJ, Murthy LI. Occupational sentinel health events: an updated list for physician recognition and public health surveillance. Am $\mathcal{J}$ Ind Med 1991;19:775-99.

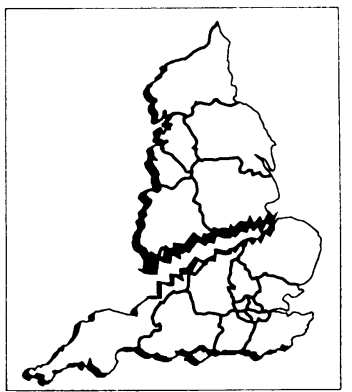

Western Infirmary, Glasgow G11 6NT Henry J Dargie, FRCP, consultant cardiologist

Department of Physical Education and Sports Science, Glasgow University, Glasgow S Grant, MSC, assistant

Correspondence to: Dr Dargie.

BMF 1991;303:910-2

\section{Exercise}

Henry J Dargie, S Grant

Exercise can take many forms and, at least until now, has been most commonly associated with the prevention of coronary heart disease. But with the accumulating evidence for preventive and therapeutic benefit in many other conditions, exercise is emerging as a key element in most national health promotion recommendations and strategies. ${ }^{1-5}$ This is hardly surprising as the ability to exercise is intrinsic to most aspects of human life and simple physical training can enable even the most unfit people and those limited by chronic illness to carry out the basic activities of modern sedentary life more efficiently and comfortably.

\section{Exercise as a key area}

The importance of coronary artery disease in Western society is not sufficient to justify including exercise as a key area. It must also be possible to conclude that exercise can favourably influence the occurrence or natural course of coronary heart disease ${ }^{7}$ and other conditions.

\section{CORONARY HEART DISEASE}

That exercise might be protective in coronary heart disease is biologically plausible even if the scientific evidence is not universally accepted.$^{89}$ Exercise could exert benefits by its effects on the main coronary risk factors. ${ }^{1011}$ Thus aerobic exercise reduces blood pressure, ${ }^{12}$ increases high density lipoprotein concentration, ${ }^{13}$ facilitates stopping smoking, ${ }^{14}$ and reduces obesity. ${ }^{15}$ Recent evidence, however, suggests that it may act on the acute phase of coronary heart disease, possibly on the coagulation mechanism or even arrhythmia. ${ }^{16} 17$

Many epidemiological studies have investigated the relation between work and leisure time exercise and coronary heart disease ${ }^{18-21}$; the evidence strongly favours the view that regular aerobic exercise of moderate intensity has a protective effect, and the benefit probably increases with the intensity of exercise. Morris, one of the earliest proponents of the protective 
effects of exercise, recently calculated that regular dynamic exercise of moderate intensity reduced the incidence of coronary events and mortality from coronary heart disease by up to $50 \% .^{17}$

Meta-analyses of controlled studies of exercise training after myocardial infarction suggest a reduction of about $25 \%$ in recurrent infarction and sudden death from heart failure. ${ }^{22}$ As most of those who die of coronary heart disease are already known to have this or other vascular disease,${ }^{23}$ the impressive contribution of exercise in secondary prevention should not be underestimated.

\section{OSTEOPOROSIS}

Hip fractures, which are a common manifestation of osteoporosis, are an important cause of morbidity, and patients often require expensive institutional care. In 1985 in England 37600 people fractured a hip, and one in four women reaching the age of 90 can be expected to have a hip fracture. ${ }^{24}$

Bone density is greater in athletes than in age matched normal sedentary people. ${ }^{25}$ Exercise programmes in postmenopausal women can also increase bone density and reverse the normal postmenopausal bone loss seen in women who do not exercise. The risk of hip fracture is substantially reduced in those who exercise regularly. Moreover, in elderly people exercise reduces the likelihood of falling..$^{26}$ It is estimated that regular exercise would reduce the risk of fracture by as much as a half, thereby preventing some 20000 hip fractures each year. ${ }^{24}$

Several strategies could help reduce the cost of health care in elderly people and among these, certainly for hip fracture, exercise is arguably the most important. The potential for exercise in facilitating greater self care remains to be explored more fully.

\section{OBESITY}

Obesity is endemic in modern society and is much more important than its modest contribution to the prevalence of coronary heart disease would suggest. Although changes in body composition with exercise are variable, it is generally accepted that total body mass and fat weight are reduced. Fat free weight remains constant or may increase slightly. Energy reduced diets, by contrast, lower both fat weight and fat free weight. When energy reduced diets are combined with exercise, the fat free weight loss is considerably less compared with programmes using only diet. ${ }^{27}$ Exercise has a complementary role in encouraging energy expenditure as well as strengthening the resolve to lose weight by promoting greater self esteem and enhanced morale. ${ }^{28}$

The physiological benefits associated with training are relatively easily attainable and could be valuable in numerous human diseases that impair human performance. Patients who might benefit include those with chronic renal failure receiving regular dialysis (who have considerably impaired physical ability), ${ }^{29}$ depression, ${ }^{30}$ respiratory disease, ${ }^{31}$ and late onset diabetes.'

\section{The case against}

Some would argue that there is no conclusive evidence from controlled trials that regular exercise reduces the number of deaths from coronary heart disease or substantially prolongs life. To demand such proof is to miss the main point about exercise, which is that it is valuable for the numerous other health benefits it confers and as a catalyst in the adoption of a healthier lifestyle.

Regular exercise has some disadvantages, which include expense-equipment, use of leisure centres, and sports complexes are not necessarily cheap-and personal injury - although exercise might prevent hip fractures in elderly people, stress fractures and joint problems associated with specific sports are well recognised but poorly catered for by the embryonic specialty of sports medicine. Occasional deaths during running events and other sporting activities underline the point that intense exercise can be dangerous, especially in those with unsuspected underlying heart disease.$^{32}$ Paradoxically, appropriate exercise training can increase exercise capacity and reduce symptoms in patients with angina ${ }^{33}$ and even with heart failure ${ }^{34}$

The government has suggested several diseases where action could be taken to improve the nation's health. ${ }^{5}$ Most human disease is multifactorial in origin, and a good example of that is coronary heart disease. But even where a single, well defined aetiological agent is identified, such as HIV in AIDS, many other factors are involved. Thus, even in apparently well defined diseases "non-specific" measures to improve the state of an individual's health could be important. Health is not merely the absence of disease, and, while few would care to define it, a sense of wellbeing and fitness should be central to any initiative to promote health. Thus exercise should be a key factor in health promotion because it can provide that feeling of wellbeing not only in those who are well (that is, those without any specific named disease) but in those with illnesses that restrict their performance. ${ }^{629} 35$

\section{Targets for exercise}

The personal targets for exercise will vary according to the primary desired effect. It is possible to identify a variety of components of exercise-skeletal (muscle, bone, and joints), cardiovascular, and energy balance. It could be argued that the type of exercise should be targeted at the disease process. Thus weight bearing or strength exercises might be best for preventing osteoporosis and hip fracture. ${ }^{6}$ Such exercise requires a small increase in energy expenditure.

For preventing coronary heart disease, dynamic exercise such as running, swimming, or cycling is necessary. A significant training effect can be obtained by exercise which raises the heart rate above resting levels by $50 \%$ of the heart rate range for 30 minutes at least three times a week. ${ }^{27}$

Several physical activities could be recommended for maintaining the energy balance at desirable level of body fatness or for preventing or treating obesity. These activities would require expending considerable amounts of energy $(8 \mathrm{~kJ} / \mathrm{min})$ over several hours - for example, by playing golf - and have little effect on the cardiovascular system.

Thus, an exercise programme can be tailored to the needs of the individual but, in general terms, components of each type of exercise can be incorporated into exercise prescriptions. The government, however, has not as yet suggested any targets for physical activity (box).

\section{Possibility of government targets for exercise}

More needs to be known about current participation in physical activity, exercise, and sport and current fitness

A national fitness survey was launched in 1990. This will provide "benchmark" data on fitness, participation, and effectiveness of different types of exercise

The government will examine the survey's findings and in the light of these consider possible targets. Physical activity will then be a prime candidate for inclusion as a key area in the health strategy 


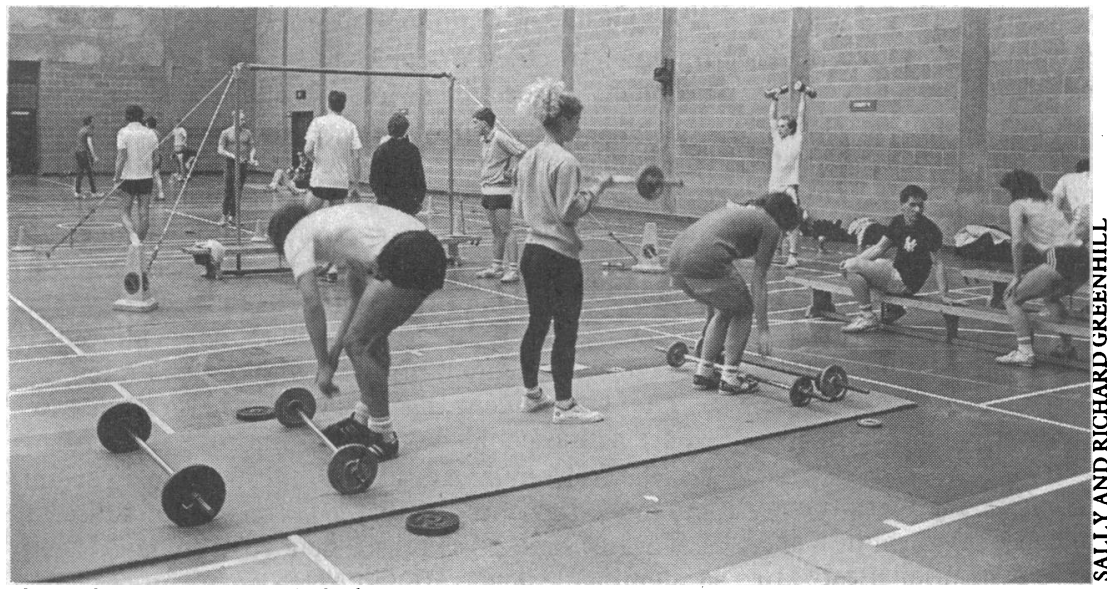

Group fitness programmes can be fun of realistic targets and proposals to improve health through regular physical activity remains to be seen. It will cost money and it is to be hoped that the government will provide the resources to establish a coordinated structure for promoting increased physical activity.

1 Royal College of Physicians Medical aspects of exercise: benefits and risks. $f R$ Coll Physicians Lond 1991;25:193-6.

2 British Cardiac Society. Working Group on Coronary Prevention. Conclusion and recommendations. Br Heart f 1987;57:188-9.

3 Scottish Home and Health Department and Scottish Health Service Advisory Council. Prevention of coronary heart disease in Scotland. Report of the working group on prevention and health promotion. Edinburgh: HMSO, 1990.

4 Scottish Home and Health Department. Health education in Scotland: a national policy statement. Edinburgh: SHHD, 1991.

Secretary of State for Health. The health of the nation. London: HMSO, 1991 (Cm 1523.)

6 Fentem PH, Bassey EJ, Turnbull NB. The new case for exercise. London: Health Education Authority, 1988.

7 Shephard RJ. Exercise in coronary heart disease. Sports Med 1986;3:26-49.

8 Durnin JVGA. Report submitted to the COMA committee on diet and cardiovascular disease. London: Department of Health, 1984

9 Leon AR. The relationship of physical activity to coronary heart disease and life expectancy. Ann N Y Acad Sci 1977;301:561-78.

\section{Strategy for reaching targets}

Individual and population strategies should be complementary. Population studies suggest that only a few people take adequate exercise. ${ }^{36}$ Adherence to exercise programmes is notoriously poor, with a typical drop out rate from supervised programmes of around $50 \%$ in various countries. Further research is needed to establish what determines the amount of exercise people take so that physical activity can be increased. ${ }^{37}$ It is unlikely that the promise of a few months extra life would be sufficiently tempting to encourage such a dramatic change of lifestyle. Such promises should be abandoned in favour of a strategy that portrays exercise as being a part of or indeed the catalyst in a lifestyle change that might include several other components, such as stopping smoking, nutritional change, reduction in stress, etc. ${ }^{38}$ To do this, exercise must be enjoyable, affordable, and accessible. Health promotion clinics in general practice could identify those who might benefit from an exercise programme.

Home based exercise programmes may be successful, though group fitness sessions at leisure centres or sports clubs can be enjoyable. Education and motivation to improve scores are sound reasons for offering regular fitness assessments. But these would require access to people with appropriate expertise, who would best be located in sports centres where community based exercise programmes could develop.

Participation of the media is essential; there are few campaigns to increase uptake of exercise and these could be increased. Encouraging walking or cycling to work together with providing exercise facilities at work and promoting of exercise and health maintenance during work could help. The establishment of many more cycle tracks and lanes could be the single measure that would be most effective in encouraging an active lifestyle. The importance of schools encouraging regular participation in sport and the adoption of an active lifestyle cannot be overstated.

\section{Problems}

A major barrier to greater participation in exercise is the relative paucity of adequate exercise and sporting facilities. This should not be a deterrent to or be a part of the case against exercise being a key area: but it would be pointless to advocate exercise to a population that had inadequate facilities to partake in it. Availability of sports centres, especially in deprived areas, and their expense are key issues. Trained professionals to supervise and advise will be required, and sports medicine facilities might also be needed.

A national fitness survey is necessary to discover the true fitness of the nation and, for England at least, this information will shortly be available. Whether the results of this survey will lead to the establishment
10 Cooper KH, Pollock ML, Martin RP, White SR, Linneryd AC, Jackson A. Physical fitness levels $v$ s selected coronary risk factors. FAMA 1976;236: $166-9$.

11 Poole GW. Exercise, coronary heart disease and risk factors. A brief report. Sports Med 1984;1:341-9.

12 Duncan JJ, Farr JE, Upton SJ, Hagan RD, Oglesby ME, Blair SN. The effects of aerobic exercise on plasma catecholamines and blood pressure in patients with mild essential hypertension. FAMA 1985;254:2609-13.

13 Goldberg L, Elliot DL. The effect of exercise on lipid metabolism in men and women. Sports Med 1987;4:307-21.

14 Marcus BH, Albrecht AE, Niaura RS, Abrams DB, Thompson PD. Usefulness of physical exercise for maintaining smoking cessation in women. $A m \mathcal{F}$ Cardiol 1991;68:406-7.

15 Bray GA. Exercise and obesity. In: Bouchard C, Shephard RJ, Stephens T, Sutton JR, McPherson BD, eds. Exercise, fitness and health. A consensus of current knowledge. Champaign, Illinois: Human Kinetics Books, 1988: 497-510.

16 Fentem P, Turnbull NB. Benefits of exercise for heart health: a report on the scientific basis. In: Exercise heart health: report of a conference organised by the coronary prevention group. London: Coronary Prevention Group, 1987: $110-25$.

17 Morris JN, Clayton DG, Everitt MG, Semmence AM, Burgess EH. Exercise in leisure time: coronary attack and death rates. Br Heart f 1990;63:325-34

8 Morris HM, Heady JA, Raffle PAB, Roberts GC, Parks JW. Coronary heart disease and physical activity of work. Lancet 1953;ii:1053-4.

19 Morris JN, Chave SPW, Adam C, Sirey C, Epstein L, Sheehan DJ. Vigorous exercise in leisure-time and the incidence of coronary heart disease. Lancet 1973;i:333-9.

20 Paffenberger RS, Weng AL, Hyde RT. Physical activity as an index of hear attack risk in college alumni. Am f E pidemiol 1978;108:161-75.

21 Powell KE, Thomson PD, Caspersen CJ, Hendrick JS. Physical activity and the incidence of coronary heart disease. Annu Rev Public Health 1987;8: 253-87.

22 O'Connor GT, Buring JE, Yusuf S, Goldhaber SZ, Olmstead EM, Paffenterger RS Jr, et al. An overview of randomised trials of rehabilitation with exercise after myocardial infarction. Circulation 1989;80:234-44. heart-attacks in East London. Lancet 1975; ii:833-8.

24 Law MR, Wald NJ, Meade TW. Strategies for prevention of osteoporosis an hip fracture. BMF 1991;303:453-9.

25 Smith EL, Gilgan C. Effects of inactivity and exercise on bone. Physician and Sports Medicine 1987;15:91-102.

26 Fiatarone MA, Marks EC, Ryan DT, Meredith CN, Lipsitz LA, Evans WJ. High-intensity strength training in nonagenarians: effects on skeleta muscle. JAMA 1990;263:3029-34

27 American College of Sports Medicine. The recommended quantity and quality of exercise for developing and maintaining cardiorespiratory and muscular fitness in healthy adults. Med Sci Sports Exerc 1990;22:265-74.

28 Garfinkel PE, Coscina DV. Discussion: exercise and obesity. In: Bouchard C, Shephard RJ, Stephens T, Sutton JR, McPherson BD, eds. Exercise, fitness and health. A consensus of current knowledge. Champaign, Illinois: Human and health. A consensus of curtent

29 Goldberg AP, Geltman E, Gavin JR, Carney RM, Hagberg JM, Delmez JA, et al. Exercise training reduces coronary risk and effectively rehabilitate haemodialysis patients. Nephron 1986;42:311-6. Stephens T, Sutton JR, McPherson BD, eds. Exercise, finess and health. A consensus of current knowledge. Champaign, Illinois: Human Kinetics Books, 1988:607-26.

31 Consensus statement. In: Bouchard C, Shephard RJ, Stephens T, Sutton JR, McPherson BD, eds. Exercise, fimess and health. A consensus of curren

32 Northcote RJ, Ballantyne D. Sudden death and sport. Sports Med 1984;1: $181-6$. with beta blockade. Br Heart f 1990;64:14-9.

34 Sullivan MJ, Higginbotham MB, Cobb FR. Exercise training in patients with severe left ventricular dysfunction, hemodynamic and metabolic effects. Circulation 1988;78:506-15.

35 Folkins $\mathrm{CH}$, Wesley ES. Physical fitness training and mental health. Am Psychol 1981;36:373-89.

36 Tunstall-Pedoe H, Smith WCS, Crombie IK, Tavendale R. Coronary risk factor and lifestyle variation across Scotland: results from the Scottish Hear Health Study. Scot Med F 1989;34:556-60.

37 Dishman RK. Exercise adherence: its impact on public health. Inj Hermans GPH, Mosterd W. Proceedings of the XXIV world congress of sporis medicine. Amsterdam: Elsevier Science Publishers, 1990:11-21.

38 Work JA. How healthy are corporate fitness programs? Physician and Sports Medicine 1989;3:226-37.
23 Tunstall-Pedoe H, Clayton D, Morris JN, Brigden W, McDonald L. Coronary

30 Brown DR. Exercise, fitness and mental health. In: Bouchard C, Shephard RJ, knowledge. Champaign, Illinois: Human Kinetics Books, 1988:3-28.

33 Tood IC Ballantyne D. Antianginal efficacy of exercise training: a comparison 